\title{
Exposing medical students to expanding populations
}

\author{
JJ Lindenthal ${ }^{1,2}$ \\ JA DeLisa ${ }^{3}$ \\ GF Heinrich ${ }^{4}$ \\ WS Calderón Gerstein ${ }^{5}$
}

'Department of Psychiatry, Institute for the Public Understanding of Health and Medicine, ${ }^{2}$ Department of Physical Medicine and Rehabilitation, New Jersey Medical School, Rutgers University, Newark, NJ, USA; ${ }^{3}$ Department of Orthopedics and Rehabilitation, University of New Mexico Health Science Center, Albuquerque, NM, USA; ${ }^{4}$ Department of Preventive Medicine and Community Health, New Jersey Medical School, Rutgers University, Newark, NJ, USA; ${ }^{5}$ Hospital Nacional Ramiro Prialé, EsSalud, Huancayo, Peru
Correspondence: Jacob Jay Lindenthal University Behavioral Science Center, Room: F-1438, I83 South Orange Avenue, University Heights, Newark, NJ $07|03-27| 4$, USA

Tel +l 9739724805

Fax +I 9739726427

Email lindenth@njms.rutgers.edu
This article was published in the following Dove Press journal:

Advances in Medical Education and Practice

19 March 2015

Number of times this article has been viewed
Abstract: Physicians are required to advocate for and counsel patients based on the best science and the interests of the individual while avoiding discrimination, ensuring equal access to health and mental services. Nonetheless, the communication gap between physician and patients has long been observed. To this end, the Institute for the Public Understanding of Health and Medicine of the Rutgers University New Jersey Medical School has expanded its efforts. This report describes two new programs: a legacy lecture series for medical students and an international "experience", in Huancayo, Peru, for medical students and faculty. The MiniMed outreach program, now in its ninth year and first described in this journal in 2012, was designed to empower the powerless to communicate more effectively with clinicians, thus improving both the effectiveness of the physician-patient relationship and health care outcomes. The approach of the two new programs and their effects on patients, particularly the underserved, and medical students and faculty, are outlined in the following article.

Keywords: MiniMed program, equal access, underserved populations, Newark Renaissance House, Kintock Group, role modeling

\section{Background}

The communication gap between patients and their physicians has long been observed, ${ }^{1-3}$ as has its negative consequences. ${ }^{4}$ Sociopolitical changes in the last several decades have effected significant shifts in the ethical imperatives associated with the physician-patient relationship. Moral and value decisions can no longer be made solely by physicians on behalf of their patients. Today's physician must be adept at dealing with ethical conflicts and reconciling his own beliefs with those of his patient. Pellegrino notes that "... the ancient precept, primum non nocere, must now apply to the integrity of the patient's value system as well as his body." ${ }^{3}$ Furthermore, physicians must be open to discussing moral choices with patients. Medicine's traditional moral authority is no longer universally accepted. Thus, it is imperative that medical educators help succeeding generations of physicians adapt to these changes, and promote the interests of the patient regardless of financial circumstances, socioeconomic status, or the health care setting. ${ }^{5}$ Physicians must continue to advocate for and counsel each patient based on the best scientific knowledge available and the interests of the individual, and work to eliminate discrimination, thus ensuring patients' equal access to health and mental health services in the community. ${ }^{5,6}$ As an example, physicians practicing in prison setting have certain ethical imperatives, especially in view of their role as agents of both the prisoner and the correctional system, but 
should nevertheless strive to base their medical judgments on providing appropriate care for the individual. ${ }^{5}$

Allowing medical students to teach the underserved can help reinforce these values. Medical students often invest time and effort into activities that will offer them the highest yield in terms of income and prestige. Devoting time to courses on medical ethics does not often fit their perceived requirements. ${ }^{7}$ Disparities in health care can begin to be addressed by having students work with minority and disadvantaged populations. The American College of Physicians is on record as advocating

...increased resources for identifying and implementing edu-

cational approaches and behavior change strategies designed

for minority audiences and the providers who treat them. ${ }^{8}$

Affording medical students the opportunity to teach and interact with culturally, economically, and socially removed social groups, in nonthreatening contexts can promote empathy, a critical variable in the ethical delivery of health care.

This report describes the expansion of the efforts of the Institute for the Public Understanding of Health and Medicine of the Rutgers University New Jersey Medical School (NJMS), first reviewed in this journal by Lindenthal and DeLisa. ${ }^{9}$ Since the publication of the original paper, two programs have been added: a legacy lecture series for medical students and an international "work experience", in Huancayo, Peru, for medical students and members of the faculty. This report further describes our outreach programs, now in their ninth year.

\section{Rutgers NJMS approach}

To enable our students to fulfill the aforementioned ethical imperatives, we expanded our MiniMed program. It now includes educational programs for groups outside of our school who would otherwise be unable to participate in the traditional MiniMed school. Medical students now prepare and deliver lectures during the academic year, to male and female inmates lodged at Kintock Group facilities and to residents of the Newark Renaissance House. A portion of the final session is devoted to a discussion of community health facilities, and a copy of each PowerPoint presentation is provided to attendees, as is a list of area health clinics. Administrative tasks, including arrangements for attendance of residents and inmates, are the responsibility of the responsibility of Kintock Group and Newark Renaissance House administrators. Medical students and administrators determine lecture topics.

\section{Outreach programs Newark Renaissance House}

The Newark Renaissance House was established in 1975 as a nonprofit residential therapeutic community with a focus on chemically dependent women and children, who are among the least empowered members of our society. The programs offered at the Newark Renaissance House serve the drug therapy needs of infants, children, adolescents, women, and men, and fall under the jurisdiction of the New Jersey Division of Child Protection and Permanency Service, as well as the Division of Mental Health and Addiction Services. Since its founding, programs have been added to address the spread of human immunodeficiency virus (HIV) infection and acquired immune deficiency syndrome (AIDS). Clients usually remain in residence between 6 and 8 months. Programs currently serve the drug therapy needs of infants, children, adolescents, women, and men. Medical students working in the Rutgers NJMS outreach program provide 16 60-minute lectures to the 38 clients enrolled in the adolescent residential program, for young men between the ages of 15 and 17, as well as to the 23 clients in the women and children's residential program devoted to the substance abuse needs of pregnant women and their children. Figure 1 provides a sample of recent

The fundamentals of contraception
Sexually transmitted diseases
Complications of pregnancy
Alcohol abuse
Drug abuse
Domestic violence
Cardiovascular diseases
Cancer
Nutrition
Trauma and sports-related injuries
Obesity
Diabetes

Figure I Sample of lectures provided to residents of Newark Renaissance House and the Kintock Group. 
lectures provided to the female residents of Renaissance House and male adolescents.

\section{The Kintock Group}

With the United States harboring more prisoners than any other nation, affording medical students with the opportunity to instruct inmates in this setting is very useful. In operation since 1985, the Kintock Group is a nonprofit organization under contract with the Federal Bureau of Prisons, the New Jersey State Parole Board, and the Department of Corrections. In addition to the program in Newark, NJ, there are two more Kintock Group programs operating in Bridgeton and in Paterson, NJ, and another in Philadelphia, PA. While each establishment has its own set of programs, the mission of all is the same - to serve as a conduit between prison and release into the community by preparing individuals to care for themselves, to practice responsible behavior, and to enter the workforce. Medical students are involved in educating 100 of the 400 residents, referred to as "parolees", in the final phase of their incarceration. About $10 \%$ of the resident population is female. The average length of stay varies between 3 and 6 months. See Figure 1 for a sample of the lectures given to inmates.

\section{MiniMed International}

Increasing immigration from Latin American countries has motivated us to join other medical schools in providing learning experiences for our medical students in the southern hemisphere. We formed a novel program, involving both students and faculty members, within the last 3 years. The program was launched in collaboration with medical colleagues in Huancayo, Peru, the capitol of the Junin province with a population of 38,000 , and with a well-established civic organization known as Chusi Wanka. The program affords Rutgers NJMS students with a 4-week health-related work experience between their first and second year of medical school. This effort provides an outstanding opportunity for medical students to learn the rudiments of health care delivery in an emerging country burdened with many preventable diseases. This is accomplished by having our medical students shadow clinicians and participate in "rounding" at the Daniel Alcides Carrión and EsSalud Hospitals, and by attending lectures at the Escuela de Medicina de la Universidad Nacional del Centro del Peru. As well, the Medical students participate in other activities - they teach young children in "HIV orphanages" about the basics of good health and disease prevention, assist their Peruvian medical student peers in learning English, and provide health-related lectures to the citizens of Huancayo.

Plans are underway to introduce a research component into the medical student experience in Peru, with faculty participation from both Peru and the United States. Paterson, NJ, about 18 miles from Newark, has a large Peruvian population, potentially allowing for comparative analyses.

With the second phase of this program, members of our faculty travel to Huancayo during the academic year to perform medical and surgical rounds, provide a week-long series of lectures to residents, and offer medical consultations. This program has proved refreshing to both our Peruvian colleagues as well as to our seasoned clinicians. Traveling with us is a librarian, whose lectures address accessing evidence-based medical information from the Internet. Participating faculty have found the experience valuable. Figure 2 provides a list of recent lectures presented by faculty members in Huancayo.

\section{Rationale}

By providing medical students, early in their training, with opportunities to communicate with diverse underserved populations in the role of instructor, we are attempting to raise perceptions, while imparting the rudiments of health education. The classroom provides a milieu conducive to breaking down of barriers to communication. Medical students learn to appreciate "where their audience is coming from" and more specifically, lay students' attributes and challenges, and their own mistaken perceptions and projections, while the route to becoming a physician is gradually elucidated. One commonly hears medical students reflecting on the intelligence, the fund of knowledge, and sophistication regarding health-related matters of the homeless, inmates, and wayward adolescents. This experience can help demystify many misconceptions, for eg, how the inmates became estranged from society. Medical students also learn about the strategies employed by drug abusers as they seek to satisfy their addiction - stunned silence followed after one medical student asked a prisoner how she was able to afford her alcohol addiction, and she revealed that she would crack open and drink the alcohol contents of cans of hairspray purchased for \$0.99. Medical students were astounded to learn that a woman incarcerated for "vagrancy" derived from an advantaged social classes and that prisoners can have siblings who are professors in medical schools.

A century ago, sociologist Charles Horton Cooley described the "looking glass self," arguing that individuals' 


Accessing medical information on the internet: an evidence-based orientation
Exsanguination in public: a preventable occurrence
The management of plastic surgical emergencies
The management of ballistic wounds
Current status of newborn care: what we do and why?
Management of newborn emergencies
Ten essential lessons in modern pediatrics
The management of gastroesophageal reflux disease (GERD) in children
Understanding fetal alcohol syndrome (FAS)
Recognizing common genetic syndromes with behavioral phenotypes
The control of smoking in children
New directions in the field of epidemiology
When to call for psychiatric consultation

Figure 2 Sample of lectures presented to medical faculty and medical students in Peru, by faculty in Huancayo, Peru.

self-conception derives from how they believe others view them..$^{10}$ Interacting in nonthreatening academic settings on the "home turf" of the individual challenges all concerned to reevaluate their self-concepts and, hopefully, encourages empathy, a significant ingredient in enhancing the efficacy of clinical care.

Our experience with these outreach programs has demonstrated their importance in exposing medical students to diverse populations as well as in instructing them in the art of teaching. The thought of being charged with educating these groups is daunting at first to students, but after several weeks, comfort and confidence levels rise greatly in the medical students and their students. Over time, medical students begin to empathize with their audiences by virtue of the latter's eagerness to learn and the personal experience they bring to the sessions. By the end of the semester, members of each group view one another with heightened respect and with the appreciation that they still have much to learn from one another. We suspect that this experience will help fortify future clinicians who will be charged with patients from increasingly diverse backgrounds.

\section{Role modeling with legacy lectures}

Role modeling is an inherent component of education and the design of the Institute for the Public Understanding of Health and Medicine. The 50 preceptors in our in-house programs, their 18 peers in the outreach programs, and the ten new medical students per year involved in MiniMed International are required to attend several legacy lectures annually provided by senior faculty members. Legacy lecturers are drawn by the medical students from among senior members of the Rutgers NJMS faculty, whose careers span 25 years; the objective is to deliver an informal discourse describing some of the many challenges posed by a lifetime career in health and medicine. The central theme of the legacy lectures focuses on both personal and professional life experiences. Lecturers are given an opportunity to reflect candidly on missed opportunities and those pursued with success, mistakes that should have been avoided and mistakes from which they learned from, recognition deemed appropriate and other activities unrequited, and the management of failure, as well as additional experiences of the lecturer's choosing. The legacy lecturer is provided with a standardized 
1. Please identify someone in your life (family, mentors, professionals in the medical field) who has inspired you and how.

2. What are some of the reasons you entered medicine?

3. What are some of the features about medicine that appeal most to you?

4. What are some of the features of medicine that you find most frustrating?

5. Are there any significant decisions involving your career that you regret? If so, please elaborate.

6. Have you experienced any identifying moments in your career that influenced your outlook on medicine? Please explain.

7. Everyone makes mistakes along the way. Would you be willing to share one or two that can prove instructive to those of us who have already chosen medicine as a career?

8. How has medicine provided you with a sense of meaning and accomplishment?

9. Can you cite one or two cases you managed that provided you with particular satisfaction?

10. Can you describe a risk you have taken that failed? How did you manage that failure and what did you learn from it?

11. What would you say are the principal sources of professional encouragement at this point in your career? In other words, what do you hope for professionally as you begin the day?

12. The cosmologist Stephen Hawking advised the following, "Concentrate on things your disability doesn't prevent you doing well. Don't regret the things it interferes with."13 How have you sought to capitalize on your strengths, while restricting potentialities not necessarily at your command?

13. We can agree that the practice of medicine has been changing dramatically in recent years. Please identify the changes you support and others you believe may be detrimental. Do you have any advice on how to deal with the increasing changes in medicine? Would you choose to enter the field of medicine again? Would you choose the same specialty?

14. Have you ever experienced a need to make an ethical decision that conflicts with the law? If so, please describe.

15. What take-home message do you have for those of us entering the field of medicine?

16. What take-home message do you have for us entering the field of medicine?

Figure 3 Questions provided to legacy lecturers.

series of questions at least 2 months in advance to facilitate adequate reflection (Figure 3). A medical student moderates the 75-minute session.

\section{Conclusion}

The mantra of our MiniMed School is that an educated patient is the doctor's best friend. Medical ethics demand an inclusive orientation directed to all citizens. Medical students are empowered by the outreach programs, as they are nonthreatening in nature. These programs are not meant to supplant health delivery experiences, such as screening clinics, but rather, to augment them. Recent empirical evidence suggests that physicians are more likely to adopt a patient-centered style of communication when they have had increased interactions with patients who ask questions, seek information, and express their concerns. ${ }^{11}$ How beneficial this approach will be in terms of health care outcomes is yet to be determined. Patients will need to know more about health owing to the changing health care landscape in the country. Empowering the powerless to communicate more 
intelligently and more effectively with clinicians should help increase both the efficiency and efficacy of the physicianpatient encounter.

\section{Disclosure}

The authors report no conflicts of interest in this work.

\section{References}

1. Evans HM. Do patients have duties? J Med Ethics. 2007;33(12): 689-694.

2. American College of Physicians. Racial and ethnic disparities in health care: a position paper of the American College of Physicians. Ann Intern Med. 2004;141:226-232.

3. Brody DS. The patient's role in clinical decision-making. Ann Intern Med. 1980;93(5):718-722.

4. Pellegrino ED. Editorial: Medical ethics, education, and the physician's image. JAMA. 1976;235(10):1043-1044.

5. Starfield B, Steinwachs D, Morris I, Bause G, Siebert S, Westin C. Patient-doctor agreement about problems needing follow-up visit. JAMA. 1979;242(4):344-346.

6. Snyder L, Leffler C; Ethics and Human Rights Committee, American College of Physicians. Ethics manual: fifth edition. Ann Intern Med. 2005;142(7):560-582.
7. Povar GJ, Blumen H, Daniel J, et al; Medicine as a Profession Managed Care Ethics Working Group. Ethics in practice: managed care and the changing health care environment: medicine as a profession managed care ethics working group statement. Ann Intern Med. 2004;141(2): 131-136.

8. Barber B. Compassion in medicine: toward new definitions and new institutions. N Engl J Med. 1976;295(17):939-943.

9. Lindenthal JJ, Delisa JA. Promoting appreciation of the study and practice of medicine: inner workings of a Mini-Med program. Adv Med Educ Pract. 2012;3:73-78.

10. Groman R, Ginsburg J; American College of Physicians. Racial and ethnic disparities in health care: a position paper of the American College of Physicians. Ann Intern Med. 2004;141(3):226-232.

11. Cooley CH. On Self and Social Organization. Chicago, IL: University of Chicago Press; 1998.

12. Cegala DJ, Post DM. The impact of patients' participation on physicians' patient-centered communication. Patient Educ Couns. 2009; 77(2):202-208.

13. Dreifus C. Life and the Cosmos, Word by Painstaking Word. New York Times, May 10, 2011, page D1. Available from: http://www.nytimes. com/2011/05/10/science/10hawking.html. Accessed on February 10, 2015.
Advances in Medical Education and Practice

\section{Publish your work in this journal}

Advances in Medical Education and Practice is an international, peerreviewed, open access journal that aims to present and publish research on Medical Education covering medical, dental, nursing and allied health care professional education. The journal covers undergraduate education, postgraduate training and continuing medical education

\section{Dovepress}

including emerging trends and innovative models linking education, research, and health care services. The manuscript management system is completely online and includes a very quick and fair peer-review system. Visit http://www.dovepress.com/testimonials.php to read real quotes from published authors. 